NAPA 66295

\title{
GLOBAL CHARACTERISTICS IN THE DIURNAL VARIATIONS OF THE THERMOSPHERIC TEMPERATURE AND COMPOSITION
}

(NASA-TM-X-66295) GLOBAL CHABACTERISTICS IN THE DIURNAL VARIATIONS OF THE THERMOSPHEEIC TEMPERATURE AND COMPOSITION (NASA) 43 p HC $\$ 4,25$ CSCL O4A

$$
\begin{aligned}
& \text { n. G. MAYR } \\
& \text { A. E. HEDIN } \\
& \text { C. A. REBER } \\
& \text { G.R. CARIGNAN }
\end{aligned}
$$

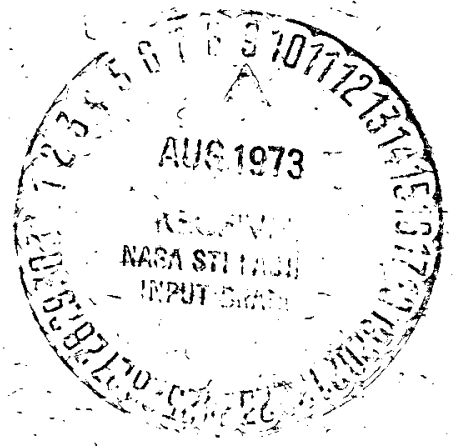

\section{GODDARD SPACE FLIGHT CEN
GREENBELT, MARYLAND}


GLOBAL CHARACTERISTICS IN THE

DIURNAL VARIATIONS OF THE

THERMOSPHERIC TEMPERATURE AND COMPOSITION

H. G. Mayr, A. E. Hedin, C. A. Reber,

and G. R. Carignan*

*University of Michigan, Ann Arbor, Michigan

Goddard Space Flight Center

Greenbelt, Maryland 


\begin{abstract}
Global characteristics in the diurnal components of OGO-6 neutral mass spectrometer measurements near $450 \mathrm{~km}$ are discussed qualitatively as well as quantitatively on the basis of a theoretical model. Observations and conclusions are summarized: (a) During equinox the temperature maximum occurs after $1600 \mathrm{LT}$ at the equator and shifts toward $1500 \mathrm{LT}$ at the poles, while the oxygen concentration at $450 \mathrm{~km}$ peaks about one hour earlier. This observed phase difference is attributed primarily to wind induced diffusion which is most effective for the mass density near $250 \mathrm{~km}$ and thus can contribute considerably to the temperature-density phase anomaly in the thermosphere, (b) there is general agreement between the magnitudes and phases of the diurnal, semidiurnal and terdiurnal temperature components at $450 \mathrm{~km}$ from theory as well as OGO-6 and radar backscatter measurements, (c) the maximum in the diurnal variation of $\mathrm{He}$ is observed near $1030 \mathrm{LT}$ consistent with theoretical results which further emphasize the importance of dynamics and diffusion, (d) during solstice conditions the diurnal temperature maximum shifts toward later local times, in substantial agreement with radar temperature measurements, (e) the temperature-oxygen density phase difference at $450 \mathrm{~km}$ is observed to decrease with latitude from the winter toward the summer hemisphere, where oxygen may even peak after the temperature at high latitudes. This effect is attributed to the diurnal variation in the $\mathrm{O}_{2}$ dissociation which becomes most significant in the summer hemisphere
\end{abstract}


where the dissociation rate is enhanced and where the atomic oxygen abundance in the lower thermosphere is significantly reduced due to the annual component in the large scale circulation. 


\section{INTRODUCTION}

The diurnal variations in the thermospheric density and temperature became a new focus of interest when radar backscatter observations revealed a temperature maximum around $1600 \mathrm{LT}$ (Carru et al. (1967), Mahajan (1969)) which was substantially later than the density maximum near $1400 \mathrm{LT}$ as inferred from satellite drag data. This discrepancy, commonly referred to as the "phase anomaly," constitutes a geophysical problem, whose explanation has been attempted by a number of authors((Rishbeth(1969), Chandra and Stubbe (1970), Mayr and Volland (1972a, 1973) and Mayr et al. (1973)). A consensus on the origin of this effect has not been reached, primarily because accurate measurements of the diurnal variations of temperature and density in the lower thermosphere are not yet available to permit convergence on particular mechanisms.

However, the recent OGO-6 neutral composition measurements (Carignan and Pinkus, 1968) near $450 \mathrm{~km}$ complement radar backscatter and satellite drag data and provide important additional inputs to the phase anomaly problem. Presumably, $\mathrm{N}_{2}$ is closest to diffusive equilibrium. Its variation is thus considered to be a good measure of the variation in the gas temperature although this assumption will be qualified further in this paper. Differences in the time response of various constituents and their relationships to the temperature $\left(\mathrm{N}_{2}\right)$ phase can hence be inferred. Furthermore, the good data coverage in local time, latitude and season permits an empirical description of these data with relatively high temporal and spatial resolution (Hedin et al. 1973a, b). 
In this paper we shall discuss the local time variations inferred from the OGO-6 neutral mass spectrometer data. The seasonal components will be treated separately (Reber et al. 1973).

\section{OGO-6 NEUTRAL COMPOSITION MEASUREMENTS}

\section{Empirical Model}

Carignan and Pinkus (1968) described the neutral mass spectrometer and its operation on OGO-6. Global properties in the distribution of composition and temperature, inferred from these measurements, were reported by Reber et al. (1971), Taeusch et al. (1971), Hedin and Reber (1972), Carignan and Reber (1971), Hedin et al. (1972, 1973a, 1973b), Hedin and Mayr (1973).

A detailed account of the statistical analysis for the empirical model of the OGO-6 mass spectrometer data is given in a separate paper (Hedin et al., 1973b). Our discussion will be based on the local time components in this OGO-6 model; thus a brief review of its properties is given here:

(1) The composition data for the model are sampled for magnetically quiet conditions $\left(A_{p} \leqslant 7, a_{p} \leqslant 12\right)$ in the $400-600 \mathrm{~km}$ altitude range.

(2) Universal time and longitudinal effects are eliminated by considering only longitudinal averages.

(3) The observed $\mathrm{N}_{2}$ variations are interpreted in terms of $\mathrm{T}_{\mathrm{g}}$ (temperature) variations whereby the assumptions are made that $\mathrm{N}_{2}$ and $\mathrm{T}_{\mathrm{g}}$ are invariant at $120 \mathrm{~km}$ and that the shape of the height distribution of $\mathrm{T}_{\mathrm{g}}$ is known, with $\mathrm{T}_{\infty}$ (exospheric temperature) being a free parameter to be determined from the observed $\mathrm{N}_{2}$ concentration. 
(4) Assuming diffusive equilibrium for all constituents at altitudes above $120 \mathrm{~km}$, the inferred temperature distribution is adopted to describe the composition of $\mathrm{N}_{2}$, $\mathrm{O}$ and $\mathrm{He}$ at $450 \mathrm{~km}$ (representative height of the measurements) and to deduce variations in $\mathrm{O}$ and $\mathrm{He}$ at $120 \mathrm{~km}$ (assuming $\mathrm{N}_{2}$ is invariant there).

(5) The atmospheric parameters $\mathrm{T}_{\infty}, \mathrm{N}_{2}, \mathrm{O}$ and $\mathrm{He}$ at $450 \mathrm{~km}$ and $\mathrm{O}$ and $\mathrm{He}$ at $120 \mathrm{~km}$ are represented in an expansion of spherical functions including diurnal, semidiurnal and teridiurnal harmonics for the local time variations, and annual and semiannual harmonics for the seasonal variations.

The model composition at $450 \mathrm{~km}$ can be regarded as a good representation of the OGO-6 measurements. Density extrapolations to this altitude level cover only about one scale height for each species and thus any uncertainties in the temperature determination are not very significant. However, two characteristics of the empirical model must be kept in mind: a. the temperatures are not measured directly but are inferred under assumptions (see point three of the previous paragraph) which are not completely justified on theoretical grounds (Volland and Mayr (1970, 1973), Mayr and Volland (1973), Mayr et al. (1973)) and b. the assumption of diffusive equilibrium is not completely valid below $200 \mathrm{~km}$ (see also Mayr and Volland (1971, 1972b), Reber and Hays (1973)) thus the inferred changes in the neutral composition at $120 \mathrm{~km}$ are probably unrealistic particularly with regard to the diurnal components which cannot be easily excited over such relatively short time periods. For these reasons, in particular, the OGO-model cannot be a substitute for in situ temperature and composition measurements in the lower thermosphere. 
On the other hand, theoretical investigations have shown that no matter how complex the dynamic properties and the phase relations of composition and temperature are in the lower thermosphere, at exospheric heights where the OGO-6 data are sampled, the temperature and the $\mathrm{N}_{2}$ concentration vary nearly in phase (Mayr et al., 1973). Thus the observed $\mathrm{N}_{2}$ variations at $450 \mathrm{~km}$ are in practice a good measure for the variations in the exospheric temperature, and consequently the inferred composition should also be reasonable at least down to $200 \mathrm{~km}$ where diffusive equilibrium holds. In our discussion of the diurnal variations we shall therefore restrict ourselves primarily to altitudes above $200 \mathrm{~km}$ which, incidentally, is also the height region in which most satellite drag data have been taken.

\section{Observations}

Figures 1 through 4 show contour plots for the local time components of $\mathrm{T}_{\mathrm{g}}$, $\mathrm{N}_{2}$, $\mathrm{O}$ and He at $450 \mathrm{~km}$ for September equinox and June solstice conditions taken from the OGO-6 model (Hedin et al., 1973b). The temperature plots describe the deviations from the global mean $\left(1098^{\circ} \mathrm{K}\right)$. The density plots represent the natural logarithms of the ratios of the variations to the global means $\left(2.16 \times 10^{6}\right.$ for $\mathrm{N}_{2}$, $6.72 \times 10^{7}$ for $\mathrm{O}$ and $3.02 \times 10^{6}$ for $\mathrm{He}$ ). In reality, seasonal and time independent latitudinal variations have to be considered superimposed on these local time components which of course, would not change the phase distributions for the various atmospheric parameters. The latitudinal variations in the times of 
density maxima are indicated with solid lines. For comparison the distributions for the temperature phase are shown in dashed lines. The diurnal variations in the OGO-6 model are not well defined during solstice conditions at high latitudes and areas of poor data coverage are shaded in Figures 1 through 4.

Considering the uncertainties in the coefficients of the empirical model we estimate the errors for the magnitudes of the diurnal variations as $\pm 15 \%$ and for the times of maxima as $\pm 0.5 \mathrm{hr}$. This phase uncertainty is small compared with the observed phase differences between He and $\mathrm{T}_{\mathrm{g}}$. However, the phase difference between $\mathrm{O}$ and $\mathrm{T}_{\mathrm{g}}$ is only marginally determined.

\section{QUALITATIVE DISCUSSION}

Figures 1 through 4 reveal a number of interesting features in the global distribution of the thermospheric composition. In the following, some of the outstanding effects are classified and discussed:

1. "Equatorial anomaly"

During conditions of equinox it is apparent that the day time bulge and the night time minimum in the $\mathrm{N}_{2}$ density and temperature are elongated around the equator. Shallow day time maxima and night time minima are observed near $\pm 20^{\circ}$ latitude indicating maximum diurnal amplitudes at these latitudes. This phenomenon resembles the equatorial anomaly in the $\mathrm{F}_{2}$ region (see the review paper by Burkard,1966) which has been attributed to ExB drifts (Hanson and Moffett, 1966) induced by electric fields from the dynamo region of the lower thermosphere. 
The connection with the equatorial anomaly has been demonstrated in Hedin and Mayr (1973). It was shown there that (a) the shallow equatorial day time minimum and night time maximum in the gas temperature tend to follow the magnetic equator when individual satellite orbits are considered over various longitudes and (b) the variations of ion drag associated with the equatorial anomaly can affect the thermospheric circulation and energy advection sufficiently to produce the observed structure in the gas temperature. From Figure 3 it is apparent that the atomic oxygen bulge is also elongated around the equator thus following to some extent the temperature pattern.

He in Figure 4 on the other hand shows a pronounced day time peak at the equator and two minima at 0200 and around $2100 \mathrm{LT}$ during night. This is in part a consequence of the semidiurnal and terdiurnal components which are most important at low latitudes although the errors in determining these modes are relatively large $(30 \%)$. Nevertheless, this tendency appears to be consistent with our picture in which the distribution of this species is significantly controlled by diffusion effects induced by the thermospheric circulation (Mayr and Volland, 1973). This process is affected by ion drag in that any decrease in the electron density at the equator would increase the wind velocity. This in turn would enhance the diffusion process, which, if dominant, would explain then the increase in the diurnal amplitude of He. 


\section{Phase Differences and Their Latitude Dependence.}

Figures 1 through 4 reveal a strong latitude dependence and systematic differences between the phases of the individual constituents. At low latitudes and during equinox conditions it is apparent that $\mathrm{N}_{2}$ (and $\mathrm{T}_{\mathrm{g}}$ ) peak latest in the afternoon (1600 LT), preceded by $\mathrm{O}$ and $\mathrm{He}$, the latter reaching its maximum already before noon. The magnitude of this effect is largest in the equatorial region where the $\mathrm{T}_{\mathrm{g}}-\mathrm{O}$ and the $\mathrm{T}_{\mathrm{g}}-\mathrm{He}$ phase differences are about one and six hours respectively. At high latitudes, however, the temperature varies more or less in phase with atomic oxygen, reaching its peak earlier in the afternoon at $1400 \mathrm{LT}$, while the He maximum shifts toward later local times (1200 LT) at high latitudes thus reducing there $\mathrm{T}_{\mathrm{g}}-\mathrm{He}$ phase differences to two hours. Although there is a half hour uncertainty in the determination of the diurnal density maxima, conceivably affecting some details in the global distribution, the observed trends are probably real.

Two factors seem to contribute. One is related to the global distribution of the solar heat input which affects directly the temperature phase, and the second one is related to the global thermospheric circulation which influences, through diffusion, primarily the lighter constituents.

The diurnal variation in the energy input, which can be treated as an impulse with a half width of 2-5 hours, produces a similar but skewed temperature variation with the peak occurring close to the time where the heat input starts to decrease. At the equator, where absorption effects are least significant, the heat input is relatively broad around noon and hence the temperature peaks 
late in the afternoon. Toward higher latitudes absorption effects become increasingly import (thus narrowing the effective width of the heat source) and thereby shift the temperature maximum toward earlier local times in agreement with the phase distributions in Figures 1 and 2. In the OGO-6 model this property is essentially described with the higher harmonics which are most significant at low latitudes. There in particular, the terdiurnal component plays the role of shifting the temperature peak toward the late afternoon. The reason for this is that the solar heat input, with its flat and elongated maximum around noon, has a relatively strong third harmonic which peaks at $1600 \mathrm{LT}$, in contrast to the energy input maxima near noon in the first two harmonics.

Wind induced diffusion causes redistribution of the minor constituents in the lower thermosphere. In this process the lighter constituents $\mathrm{O}$ and He are transported from late afternoon toward early morning hours such that their diurnal peaks are shifted away from the temperature maximum toward earlier local times (Mayr and Volland, 1972, 1973a). This effect is more important for He than for $O$. Furthermore, the temperature induced variation in the composition, which competes with the diffusion effect and which tends to produce density variations in phase with the temperature, is more effective for the heavier constituent $O$. For both these reasons the He- $\mathrm{T}_{\mathrm{g}}\left(\mathrm{N}_{2}\right)$ phase difference should be larger than that between $O$ and $T_{\mathrm{g}}$ in substantial agreement with the OGO-6 observations in Figures 1 through 4 . 
The observed latitude dependence in the phase differences between $\mathrm{O}, \mathrm{He}$ and Tg are consistent with certain dynamic properties of energy advection and diffusion which are related to the horizontal scales in the global thermospheric circulation. Diffusive mass transport in $\mathrm{O}$ and $\mathrm{He}$ is to a great extent proportional to the vertical wind velocity. This in turn increases with increasing divergence of the horizontal wind field. For a given horizontal wind velocity the diffusion effect thus increases inversely proportional to the scale of the circulation or with the number of circulation cells (see Mayr and Volland, 1973b). At low latitudes, where the higher harmonics in the diurnal variations are most significant, the diffusion process is thus most effective, causing the phase differences between $\mathrm{He}, \mathrm{O}$, and $\mathrm{T}_{\mathrm{g}}$ to increase toward the equator (disregarding the low latitude structures induced by the equatorial anomaly in the $\mathrm{F}_{2}$ - region). In parallel, heat advection, with global characteristics similar to diffusion, also becomes more effective toward the equator thus damping there the temperature amplitude relative to what it would be in the absence of this energy transport. It follows then that the temperature induced variations in the composition are relatively less significant at low latitudes hence further contributing there to the increased phase difference between the gas temperature and the lighter constituents (Mayr et al. 1973).

3. Seasonal Effects.

Figures 1 through 3 show that the diurnal variations for $O$ and $T_{g}\left(N_{2}\right)$ are significantly different in the summer and winter hemispheres, while the He 
distribution in Figure 4 is fairly symmetrical with respect to the equator. We recognize that the atmosphere is poorly defined by the OGO- 6 model above $50^{\circ}$ latitudes. Nevertheless, even at low to mid-latitudes there are a number of pronounced features in the composition such as: (1) the increasing $T_{g}\left(N_{2}\right)$ amplitude between $+30^{\circ}$ and $-30^{\circ}$ latitudes from the summer toward the winter hemisphere; (2) the broadening of the diurnal $\mathrm{T}_{\mathrm{g}}\left(\mathrm{N}_{2}\right)$ and $\mathrm{O}$ maxima in the summer hemisphere accompanied by a shift of the $\mathrm{T}_{\mathrm{g}}\left(\mathrm{N}_{2}\right)$ peaks toward later local times near the subsolar point; and (3) the decrease of the phase difference between $O$ and $T_{g}$ in the summer hemisphere with some indication that oxygen might even peak later than the gas temperature at high latitudes.

A number of factors contribute to these effects, some of which we shall further discuss quantitatively in the subsequent chapter of this paper. In the summer hemisphere the time span of solar illumination increases thus producing there the observed broadening in the diurnal maxima of oxygen and temperature while shifting their peaks toward later local times. With the widening of the solar heat input, the ratio of the diurnal to the local time average components decreases in summer relative to winter thus contributing to the winter maximum at $-30^{\circ}$ latitude in the diurnal temperature amplitude. The actual magnitudes of these effects are probably also affected by the seasonal modulation of the diurnal wind circulation as well as by the seasonal (winter to summer) 
variations in the local time average components of temperature and composition. While the former tends to damp the horizontal variations in $T_{g}$, the latter may substantially contribute to the observed increase of the temperature amplitude in winter when the average background pressure (internal energy) is lower relative to the summer hemisphere.

The seasonal component in the diurnal variations of atomic oxygen, and in particular its phase relation to $\mathrm{T}_{\mathrm{g}}$, is governed by a complex superposition of transport processes related to temperature variations, wind circulation and dissociation of $\mathrm{O}_{2}$

$$
\mathrm{O}_{2}+\mathrm{h} \nu \rightarrow \mathrm{O}+\mathrm{O}
$$

Among these processes, dissociation of $\mathrm{O}_{2}$ probably contributes most to the seasonal variations. The significance of this reaction is proportional to the dissociation rate

$$
\mathrm{Q}_{\mathrm{Di} \mathrm{s}} \propto 2 \mathrm{~F}\left[\mathrm{O}_{2}\right]
$$

(where $\mathrm{F}$ is the dissociating solar flux in the Schumann Runge continuum and $\left[\mathrm{O}_{2}\right]$ is the concentration of $\mathrm{O}_{2}$ ) and it is inversely proportional to the amount (reservoir) of atomic oxygen. From winter to summer the dissociation rate increases while the local time average atomic oxygen concentration decreases owing to mass transport associated with the annual and semiannual components in the global circulation (Mayr and Volland, 1971, 1972b). For both these reasons the dissociation process should thus be much more important for the diurnal variations in summer than in 
winter. With dissociation maximizing around noon its cumulative effect tends to produce a diurnal maximum in $O$ during the late afternoon, thereby shifting the oxygen phase away from the temperature toward later local times. This trend is exactly opposite to the wind induced diffusion process, discussed earlier, which tends to shift the oxygen phase away from the temperature toward earlier local times, and both processes are different from the temperature induced variations which would tend to keep atomic oxygen in phase with the gas temperature.

\section{QUANTITATIVE DISCUSSION}

Our quantitative discussion will be based on a quasi-three dimensional model (Mayr et al. 1973). Applying perturbation theory the equations of energy, mass and momentum conservation are solved for a two component gas whereby the momentum transfer between the two constituents (diffusion) is considered in a self consistent form. In particular two versions are being used: one in which oxygen diffuses through $\mathrm{N}_{2}\left(+\mathrm{O}_{2}\right)$; and another one in which He diffuses through a fictitious gas component with mass and density corresponding to the mixture of $\mathrm{O}, \mathrm{N}_{2}$ and $\mathrm{O}_{2}$. For He,thermal diffusion has also been considered. We consider the first version to be realistic with regard to temperature and wind fieldssince the energetics of the thermosphere is essentially determined below $500 \mathrm{~km}$ where $\mathrm{O}$ and $\mathrm{N}_{2}$ are the major constituents. The second version, however, serves only to give an estimate for the diurnal variations of He and is probably not realistic energetically. 
From a Fourier analysis of solar heat input calculations by Harris and Priester (1962) the relative magnitudes and height distributions of the diurnal, semidiurnal and terdiurnal components are adopted as shown for the equator in Figure 5. The absolute magnitudes are determined such that the resulting theoretical temperature amplitude in the first diurnal component agrees with OGO-6 observations. This model of the heat input distribution deviates from the one in Mayr et al. (1973) in that the amplitude of the third harmonic is considered constant below $200 \mathrm{~km}$ reflecting the importance of absorption. We retain, however, all other assumptions regarding the latitude dependence and the phase variations with height. Furthermore, we have extended the earlier analysis by including dissociation (Equation 1). Figure 5 shows the amplitudes of the dissociation rates for the diurnal and semidiurnal components at the equator. Considering that dissociation is only significant in the lower thermosphere and mesosphere we neglected its third harmonic consistent with the low heat input rates in this component. It is assumed that the maxima in the diurnal components of the dissociation rate occur at $1200 \mathrm{LT}$ and that the amplitudes decrease with latitude proportional to $\sin \theta$ and $\sin ^{2} \theta$ for the diurnal and semidiurnal components respectively $(\theta=$ colatitude $)$.

For the local time average ion drag an electron density distribution was adopted with an $\mathrm{F}_{2}$ maximum of $1.3 \times 10^{6} / \mathrm{cc}$ at $300 \mathrm{~km}$ and an electron density of $3.5 \times 10^{4}$ at $120 \mathrm{~km}$. The diurnal component of the electron density was assumed to vary with a relative amplitude of 0.5 and a maximum at 1200 LT. 
All other input parameters such as the coefficients for heat conduction, viscosity and molecular and eddy diffusion were the same as in previous papers (Mayr and Volland, 1973a; Mayr et al. 1973).

\section{Tidal Components}

The computed diurnal variations in $T_{g}$, mass density and He concentration are presented in Figure 6 for the equator. For comparison are shown the OGO-6 $\mathrm{T}_{\mathrm{g}}$, oxygen (mass density) and He measurements at $450 \mathrm{~km}$, as well as the diurnal variations in the mass density inferred from satellite drag (Jacchia, 1971) under similar solar activity conditions. To simplify the presentation the theoretical He distribution is only given for $450 \mathrm{~km}$ while the mass density and temperature variations are shown for various heights.

The agreement in the magnitude of the diurnal temperature variation is not significant since the heat input for the first diurnal component was adjusted such that the amplitude (not phase) in the theoretical temperature component matched the corresponding $\mathrm{T}_{\mathrm{g}}$ tide in the OGO-6 measurements. However, the relative amplitudes of the diurnal, semidiurnal and terdiurnal tides as well as the temperature phase and its relation to the phases of $\mathrm{He}$ and $\mathrm{O}$ at $450 \mathrm{~km}$ are significant, since in the framework of the theoretical model (Mayr et al. 1973) no adjustments or assumptions have been made to control these properties.

From Figure 6 it is apparent that the maximum in the theoretical temperature variation occurs at $1600 \mathrm{LT}$ in close agreement with the OGO-6 observations. Furthermore the computed maximum in the mass density near $1500 \mathrm{LT}$ is in 
substantial agreement with both the OGO-6 and satellite drag data. For He the phases agree reasonably well in particular for the dominant first harmonic which produces a maximum near $1100 \mathrm{LT}$ in the theory. Due to the second and third harmonics, however, an elongated He bulge develops which has a shallow maximum in the leading edge after $1200 \mathrm{LT}$. However, in view of relatively large errors associated with the semidiurnal and terdiurnal components of the empirical He model from OGO-6 the discrepancy between theory and observation may not be significant.

The physical processes for the phase shift of He and oxygen away from the temperature toward earlier local times, revealed in the theoretical results in Figure 6, have been quantitatively discussed in some detail (Mayr and Volland $(1972,1973 a)$, Mayr et al.(1973)). In this theory it is energy and mass transport associated with the thermospheric circulation which contribute to the phase differences between individual constituents by (a) producing a phase shift in the temperature toward earlier local times at lower altitudes and (b) inducing deviations from diffusive equilibrium in the lower thermosphere such that the lighter and minor constituents tend to peak $90^{\circ}$ (6 hours for the diurnal component) before the temperature maximum.

This is illustrated in Figure 7 where the theoretical phase distributions are shown together with the phases of mass density and temperature deduced from the OGO-6 measurements. The temperature determination from $\mathrm{N}_{2}$ measurements on OGO-6 is based on the assumption that $\mathrm{N}_{2}$ is invariant at $120 \mathrm{~km}$ and that the temperature phase is height independent. Thus the $\mathrm{N}_{2}$ observations at $450 \mathrm{~km}$ can only produce an "effective temperature phase" representative 
of the entire thermospheric temperature structure, even if $\mathrm{N}_{2}$ is in perfect diffusive equilibrium. In reality, the $\mathrm{N}_{2}$ maximum may occur either before or after the $T_{g}$ peak at exospheric heights depending on whether the temperature phase shifts at lower heights toward earlier or later local times respectively. On the basis of the theoretical model discussed here the temperature should therefore actually peak after the $\mathrm{N}_{2}$ density. The $\mathrm{N}_{2}-\mathrm{T}_{\mathrm{g}}$ phase difference, however, is small due to (1) the large influence of the temperature phase above $200 \mathrm{~km}$ which is almost constant and (2) due to the drag (diffusive) interaction with $O$ which tends to shift the $\mathrm{N}_{2}$ phase toward later local times, thereby partially compensating the effect of the earlier temperature phase at lower heights. With this qualification in mind, the extrapolation of OGO 6 temperature and density variations to lower heights is not very meaningful below $200 \mathrm{~km}$, particularly not for $\mathrm{O}$ and He which are not in complete diffusive equilibrium there. Down to this altitude theory and "observations" agree within the \pm 0.5 hour uncertainty in the phase determination at $450 \mathrm{~km}$. The agreement is particularly good in the magnitude of the temperature-density phase difference as well as its height dependence, which clearly indicates a widening of the phase discrepancy at lower altitudes. Since it is inherent in the present analysis of satellite drag data that the density phase is height independent it is then likely that these observations only produce a phase representative of some intermediate altitude region around $300 \mathrm{~km}$, where we would also put the density phase at $1430 \mathrm{LT}$. 
The density extrapolation from the OGO-6 measurements to greater heights suggests that the density-temperature phase difference decreases further up to $600 \mathrm{~km}$ where it starts again to widen due to the growing importance of He. This reversion in the phase distribution is particularly significant in the winter hemisphere where the He content is considerably enhanced; likewise it is least important in summer where the He density reaches its minimum.

Magnitudes and phases of the three diurnal temperature harmonics are comparea in Table 1. Considering that in our theory $P_{1}^{1}, P_{2}^{2}$ and $P_{3}^{3}$ are the spherical harmonics associated with the diurnal, semidiurnal and terdiurnal components, we have chosen only the corresponding coefficients from the OGO-6 model. Similarly, the radar temperature measurements reported by Salah and Evans (1973) at $45^{\circ}$ were extrapolated to the equator adopting the latitude dependences $\mathrm{P}_{1}^{1}(\sin \theta), \mathrm{P}_{2}^{2}\left(\sin ^{2} \theta\right)$ and $\mathrm{P}_{3}^{3}\left(\sin ^{3} \theta\right)$ for the three harmonics. Table 1 reveals generally good agreement between the three data sets. The exception is the magnitude of the semidiurnal tide, inferred from OGO-6, which is by about a factor of two lower than those inferred from theory or radar temperature measurements. Although the errors in the OGO-6 measurements of the semidiurnal tide are relatively large (20\%) they cannot completely account for this disagreement. This discrepancy may be due to the fact that the OGO-6 temperature model is not based on temperature but on $\mathrm{N}_{2}$ measurements. On the other hand the theoretical description of the semidiurnal component is problematic in that nonlinear effects and energy coupling from the lower atmosphere 
play a major role. Considering the extrapolation procedure adopted for the radar temperature components their agreement with the theory is perhaps not convincing enough either to rule against the small semidiurnal component in the OGO-6 data.

\section{Seasonal Variations}

Figure $8 \mathrm{~A}$ shows the latitudinal variations in the local times of maxima for $\mathrm{T}_{\mathrm{g}}, \mathrm{O}$ and He from the OGO-6 observations during June solstice and September equinox. Figure $8 \mathrm{~B}$ shows the phase differences for $\mathrm{O}$ and He with respect to $\mathrm{T}_{\mathrm{g}}$. While for He there is relatively little change between summer and winter, the $\mathrm{T}_{\mathrm{g}}-\mathrm{O}$ phase difference reverses from the winter toward the summer hemisphere. This feature is further characterized in Figure $8 \mathrm{C}$ where the difference in the times of maxima between equinox and solstice conditions is shown for $O$. From this it is apparent that relative to equinox the oxygen phase shifts toward later local times in summer and toward earlier local times in winter.

We suggest that this feature is caused by the diurnal variation in $\mathrm{O}_{2}$ dissociation as it is seasonally modulated by the winter to summer decrease of the oxygen content of the lower thermosphere (see the qualitative discussion in this paper). To demonstrate the significance of this effect a parametric study has been carried out for mid-latitudes, whereby the diurnal amplitude of the dissociation rate, as well as the oxygen concentration at $120 \mathrm{~km}$ have been varied independently. Figure 9 shows the diurnal component of the $T_{g}-O$ phase difference at $450 \mathrm{~km}$ as a function of these two parameters. 
For zero dissociation rate the phase difference is almost an hour at $450 \mathrm{~km}$ (and almost two hours at $250 \mathrm{~km}$ ). As has been pointed out before, this phase difference is to a great extent generated by diffusion and for this process it is important that oxygen is lighter than the mean molecular mass and is a minor constituent in the lower thermosphere. With increasing oxygen concentration the latter condition deteriorates, thus diminishing the importance of diffusion. Hence the $T_{g}-O$ phase difference slightly decreases, as can be seen from Figure 9 (when dissociation is neglected).

The diurnal variations in $\mathrm{O}_{2}$ dissociation, which produce atomic oxygen at a rate that peaks during noon, induces diurnal variations in $\mathrm{O}$ which tend to peak near dusk. With the production rate being independent of $O$, the significance of dissociation increases as the background density (local time average) of atomic oxygen decreases. The oxygen phase is thus delayed toward later local times when, for a particular dissociation rate, the oxygen concentration is decreased and or when the dissociation rate is increased for a given oxygen concentration.

Following an interpretation of the $\mathrm{F}_{2}$-region winter anomaly by Johnson (1964) and King (1964) it has been shown theoretically that the annual component in the thermospheric wind field induces about a factor of three decrease in the atomic oxygen concentration of the lower thermosphere between winter and summer (Mayr and Volland $(1971,1972 b)$ ). This seasonal effect in the neutral composition is found to be consistent with the OGO-6 neutral mass spectrometer measurements at $450 \mathrm{~km}$ (Hedin et al. 1973, Reber et al., 1973). Figure 9 should therefore be 
read in the sense that lower oxygen concentrations (and higher dissociation rates) are representative for summer conditions while higher oxygen concentrations (and lower dissociation rates) represent winter conditions. For a wide range of dissociation rates (between $2 \times 10^{-5}$ and $5 \times 10^{-5}$ at $120 \mathrm{~km}$ ) a factor of three decrease in atomic oxygen thus changes the $\mathrm{T}_{\mathrm{g}}-\mathrm{O}$ phase difference by about an hour, from oxygen peaking substantially before the temperature in winter toward oxygen being in phase or peaking slightly after the temperature in summer. Trend and magnitude of this effect are thus in substantial agreement with the observed phase distribution for $\mathrm{O}$ revealed in Figure 8.

These results are summarized in Figure 10 for which we computed the diurnal variations of temperature and oxygen concentration at $450 \mathrm{~km}$ in the summer and winter hemispheres. Inputs on the local time averages of temperature and composition were taken from the OGO-6 measurements (Hedin et al. 1973b) which show that at $120 \mathrm{~km}$ O should (a) decrease by a factor of 1.5 from the equator toward the summer hemisphere and (b) increase by a factor of 1.3 from the equator toward the winter hemispheres at midlatitudes. The exospheric temperature is observed to change from $1098^{\circ} \mathrm{K}$ at the equator to $1170^{\circ} \mathrm{K}$ and $910^{\circ} \mathrm{K}$ in the summer and winter hemisphere respectively. The density variations in Figure 10 are normalized to 1 for the local time average equatorial oxygen concentration at $450 \mathrm{~km}$. For the heat input rate it was assumed that the three harmonics vary with latitude like $\sin \left(\theta-\theta_{s}\right), \sin ^{2}\left(\theta-\theta_{s}\right), \sin ^{3}\left(\theta-\theta_{s}\right)$, where $\theta_{\mathrm{s}}$ is the colatitude of the solar declination. The latter assumption was 
made to account for the fact that absorption effects are least significant at subsolar latitudes and thus higher harmonics, particularly the terdiurnal component, are most significant there. It is apparent from Figure 10 that the theory can basically reproduce the phase shift of $T_{g}$ toward later local times in summer and the narrowing of the density-temperature phase difference from winter to summer; however it cannot reproduce the large diurnal amplitude in winter, a feature which may in part be related to the winter enhancement in the $\mathrm{F}_{2}$ region ionization (winter anomaly).

\section{SUMMARY AND CONCLUSION}

Global characteristics in the diurnal components of OGO-6 neutral mass spectrometer measurements (Carignan and Pinkus, 1968) near $450 \mathrm{~km}$, which have been described empirically in analytic form (Hedin et al. 1973b), are discussed qualitatively as well as quantitatively on the basis of a theoretical model (Mayr et al. 1973).

The observations and conclusions are summarized:

(a) During equinox the diurnal temperature maximum occurs after $1600 \mathrm{LT}$ at the equator and shifts toward $1500 \mathrm{LT}$ near the poles due to the diminishing importance of higher harmonics (particularly the terdiurnal one) which describe the broadening of the diurnal solar heat input at subsolar latitudes and due to the decreasing ion drag. 
(b) During equinox the oxygen concentration at $450 \mathrm{~km}$ is observed to peak near $1500 \mathrm{LT}$ at the equator and shift toward $1430 \mathrm{LT}$ at the poles. This phase difference between $\mathrm{T}_{\mathrm{g}}$ and $\mathrm{O}$ is consistent with a theoretical prediction (Mayr and Volland, 1972) that attributed this effect primarily to wind induced diffusion. This $\mathrm{T}_{\mathrm{g}}-\mathrm{O}$ phase difference increases toward lower altitudes, thus producing a phase difference between $T_{g}$ and mass density of about 1.5 hours at $250 \mathrm{~km}$ which contributes considerably to the phase anomaly in thermosphere.

(c) From observations as well as theoretical analysis it is concluded that the phase of the mass density as well as its difference with respect to the temperature can vary by more than an hour between 200 and $600 \mathrm{~km}$ and by almost an hour between equator and poles during equinox conditions.

(d) There is general agreement between the magnitudes and phases of the diurnal, semidiurnal and terdiurnal temperature components at $450 \mathrm{~km}$ from theory as well as OGO-6 and radar backscatter measurements, except for the magnitude of the semidiurnal tide which is somewhat small $(2.1 \%$ at the equator) in the OGO-6 analysis. In particular, the observed large amplitude $(3 \%)$ and late phase $(1630 \mathrm{LT})$ in the terdiurnal tide are reproduced theoretically suggesting that it is excited directly by the solar UV component associated with the elongation of the heat input maximum around noon.

(e) The maximum in the diurnal variation of He is observed near $1030 \mathrm{LT}$, in substantial agreement with the theoretical results, thus emphasizing the importance of wind induced diffusion which primarily accounts for this large phase difference with respect to $\mathrm{T}_{\mathrm{g}}$. 
(f) From winter to summer the temperature maximum is observed to shift toward later local times in agreement with radar temperature measurements (Salah and Evans, 1973). This effect is attributed to the broadening of the solar heat input maximum in summer, particularly near subsolar latitudes where the time period of illumination is long and absorption effects are least significant.

(g) During solstice conditions it is observed that the positive phase difference between $T_{g}$ and $O$ decreases from the winter toward the summer hemisphere with some indication that $O$ might even peak after $T_{g}$ at high latitudes. This effect, which indicates significant variations in the phase of the mass density between winter and summer, is attributed to the diurnal variations in $\mathrm{O}_{2}$ dissociation which produces oxygen during daytime and thus tends to shift the $O$ peak toward later local times. Between winter and summer the significance of dissociation increases due to the increasing dissociation rate but most importantly due to the decreasing $O$ concentration in the lower thermosphere. The greater importance of dissociation in summer thus compensates (or even overcompensates) the wind induced diffusion which normally shifts the oxygen peak away from the temperature toward earlier local times.

Important insight into the thermosphere structure has been gained from the OGO-6 composition measurements around $450 \mathrm{~km}$. However, to converge with some degree of uniqueness upon the mechanisms responsible for these structures it will be necessary that similar global observations, combined 
with in situ temperature and wind measurements, be carried out at lower altitudes where the dynamics and energetics of the thermosphere, as well as coupling with the mesosphere, have the greatest impact. 


\section{REFERENCES}

1. Burkard, O. M., Some remarks on papers concerning the geomagnetic anomaly of the $\mathrm{F}_{2}$-layer, Journ. Atm. Terr. Phys., 28, 1129, 1966.

2. Carignan, G. R., and W. H. Pinkus, OGO-F04 experiment description, Tech. Note 08041-3-T, Univ. of Mich., Ann Arbor, 1968.

3. Carignan, G. R. and C. A. Reber, The neutral atmosphere response to the large magnetic storm of 8 March $1970, \mathrm{EOS}, 52,871,1971$.

4. Carru, H., M. Petit and P. Waldteufel, On the diurnal variation of the thermopause temperature, Planet. Space Sci., 15, 944, 1967.

5. Chandra, S. and P. Stubbe, The diurnal phase anomaly in the upper thermospheric density and temperature, Planet. Space Sci., 18, 1021, 1970.

6. Hanson, W. B., and R. J. Moffett, Ionization transport effects in the equatorial $\mathrm{F}_{2}$-region, J. Geophys. Res., 71, 5559, 1966.

7. Harris, $I_{\bullet}$, and W. Priester, Time dependent structure of the upper atmosphere, J. Atmos. Terr. Phys., 29, 1429, 1967.

8. Hedin, A. E. and C. A. Reber, Longitudinal variations of thermospheric composition indicating magnetic control of polar heat input, J. Geophys. Res., 77, 2871, 1972.

9. Hedin, A. E., H. G. Mayr, C. A. Reber, G. R. Carignan, and N. W. Spencer, Empirical model of global thermospheric temperature and composition based on data from the OGO-6 quadrupole mass spectrometer, NASADocument X-621-73-37, 1972. 
10. Hedin, A. E., and H. G. Mayr, Magnetic control of the near equatorial neutral thermosphere, J. Geophys. Res., 78, 1688, 1973.

11. Hedin, A. E., H. G. Mayr, C. A. Reber, G. R. Carignan and N. W. Spencer, A global empirical model of thermospheric composition based on OGO-6 mass spectrometer measurements, in press for Space Research XIII, 1973a.

12. Hedin, A. E., H. G. Mayr, C. A. Reber, N. W. Spencer and G. R. Carignan, Empirical model of global thermospheric temperature and composition based on data from the OGO-6 quadrupole mass spectrometer, EOS, 54,398 , 1973, in preparation for publication $1973 \mathrm{~b}$.

13. Johnson, F.S., Circulation at ionospheric levels, Rep. Southwest Center of Adv. Stud., Contract CW-11, 10531, Cambridge, Mass., 1964.

14. Jacchia, L. G., Revised static models of the thermosphere and exosphere with empirical temperature profiles, Smithsonian Astrophysical Observatory, Special Report, 332, 1971.

15. King, G. A. M., The dissociation of oxygen and high level circulation in the atmosphere, J. Atmos. Sci., 21, 231, 1964.

16. Mahajan, K. K., Diurnal variation of ion temperature, J. Atmos. Terr. Phys., $31,93,1969$.

17. Mayr, H. G., and H. Volland, Semiannual variations in the neutral composition, Ann. Geophys., 27, 513, 1971.

18. Mayr, H. G. and H. Volland, Diffusion model for the phase delay between thermospheric density and temperature, J. Geophys. Res., 77, 2359, 1972a. 
19. Mayr, H. G., and H. Volland, Theoretical model for the latitude dependence in the thermospheric annual and semiannual variations, J. Geophys. Res., $77,6774,1972 \mathrm{~b}$.

20. Mayr, H. G., and H. Volland, Two component model for the diurnal variations in the thermospheric composition, J. Atm. Terr. Phys., 35, 669, 1973a.

21. Mayr, H. Go, and H. Volland, Magnetic storm characteristics of the thermosphere, J. Geophys. Res., 78, 2251, $1973 \mathrm{~b}$.

22. Mayr, H. G., I. Harris and H. Volland, Theory of the phase anomaly in the thermosphere, EOS, 54, 400, 1973, NASA Document X-621-73-71, 1973, in press for J. Geophys. Res.

23. Reber, C. A., D. N. Harpold, R. Horowitz, and A. E. Hedin, Horizontal distribution of helium in the earth's upper atmosphere, J. Geophys. Res., $76,1845,1971$.

24. Reber, C. A., and P. B. Hays, Thermospheric wind effects on the distribution of helium and argon in the earth's upper atmosphere, J. Geophys. Res., $78,2980,1973$.

25. Reber, C. A., A. E. Hedin, H. G. Mayr and G. R. Carignan, Latitudinal/ seasonal characteristics of the thermospheric composition,in preparation for publication, 1973.

26. Rishbeth, H., On the phase of the diurnal bulge in the thermosphere, Ann. Geophys., 25, 495, 1969. 
27. Salah, J. E., and J. V. Evans, Measurements of thermospheric temperatures by incoherent scatter radar, Space Research XV, 1973.

28. Taeusch, D. R., G. R. Carignan, and C. A. Reber, Neutral composition variations above 400 kilometer during a magnetic storm, J. Geophys. Res., $27,8318,1971$.

29. Volland, H., and H. G. Mayr, A theory of the diurnal variations of the thermosphere, Ann. Geophys., 26, 907, 1970.

30. Volland, H., and H. G. Mayr, A numerical study of the three dimensional diurnal variations within the thermosphere, Ann. Geophys., 29, 1102, 1973. 


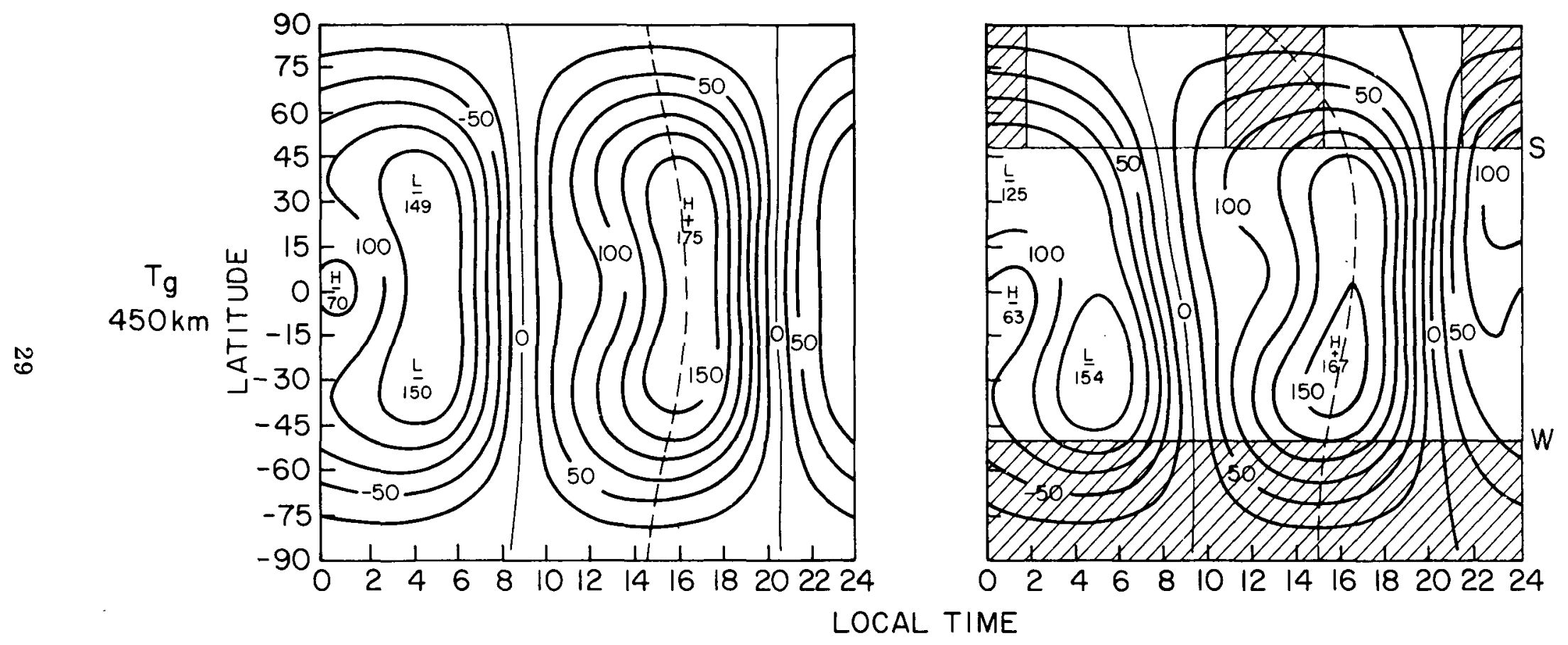

Figure i. Diurnal variations in the exospheric temperature inferred from the $0 \mathrm{GO}-6 \mathrm{~N}_{2}$ measurements around $450 \mathrm{~km}$. The contour plots represent temperature differences from the local time average component for September equinox (left) and June solstice (right) conditions. 


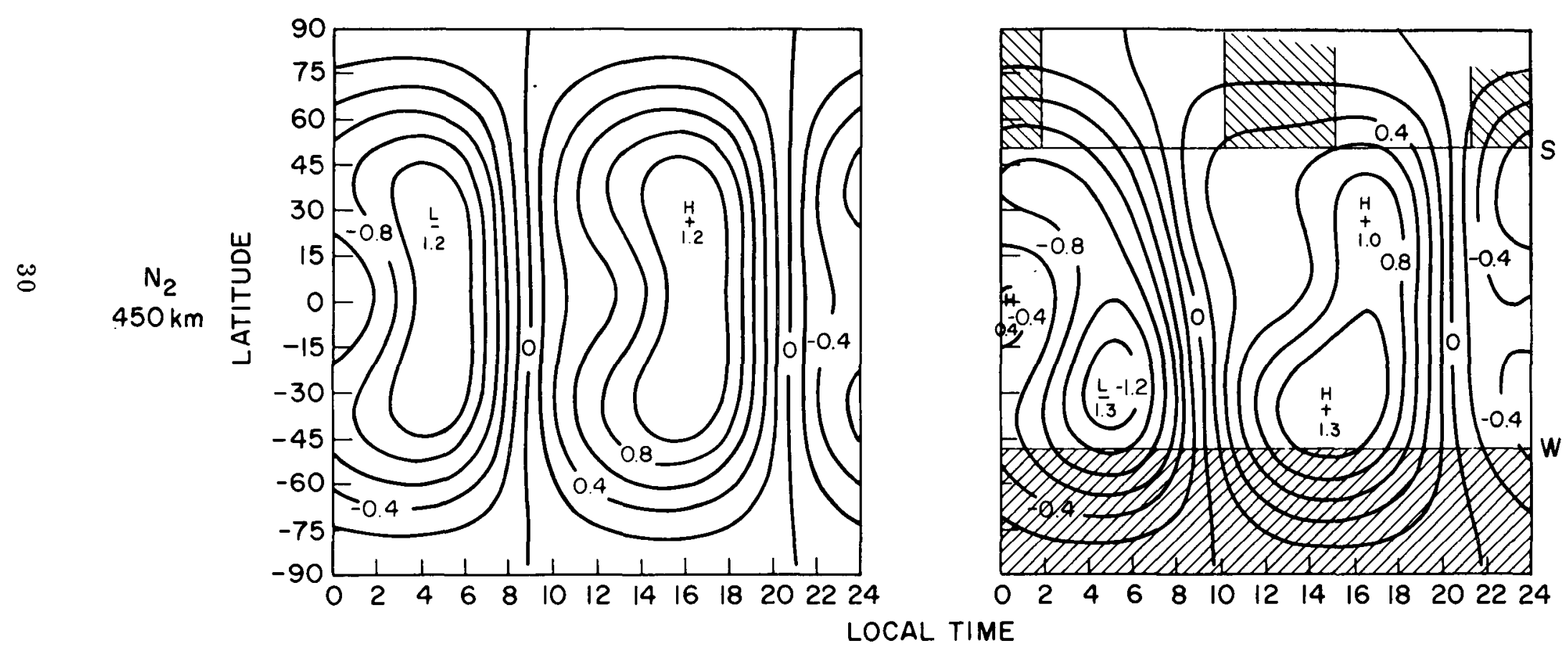

Figure 2. Contour plots of the logarithm (base e) of the ratio of the $450 \mathrm{~km} \mathrm{~N}$ densities to the local time average component for equinox and solstice conditions. 


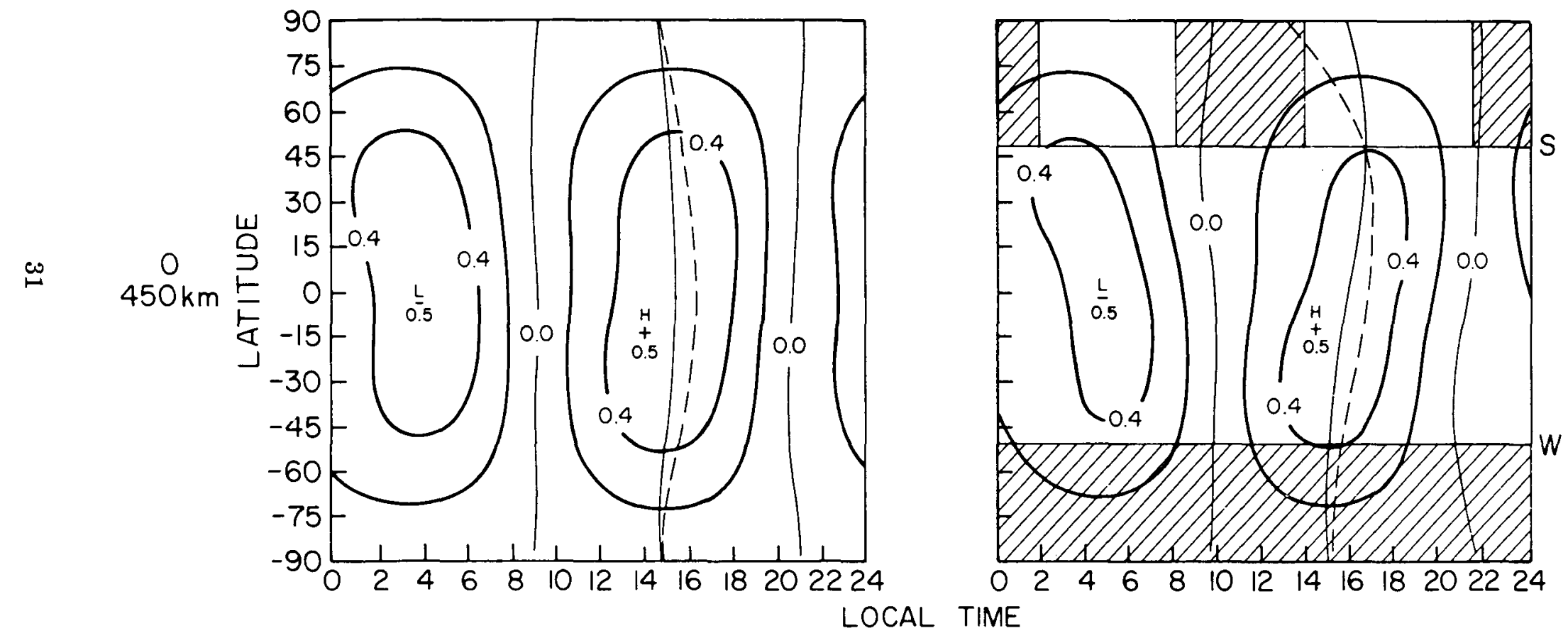

Figure 3. Contour plots of the logarithm (base e) of the ratio of the $450 \mathrm{~km} \mathrm{O}$ densities to the local time average component for equinox and solstice conditions. 


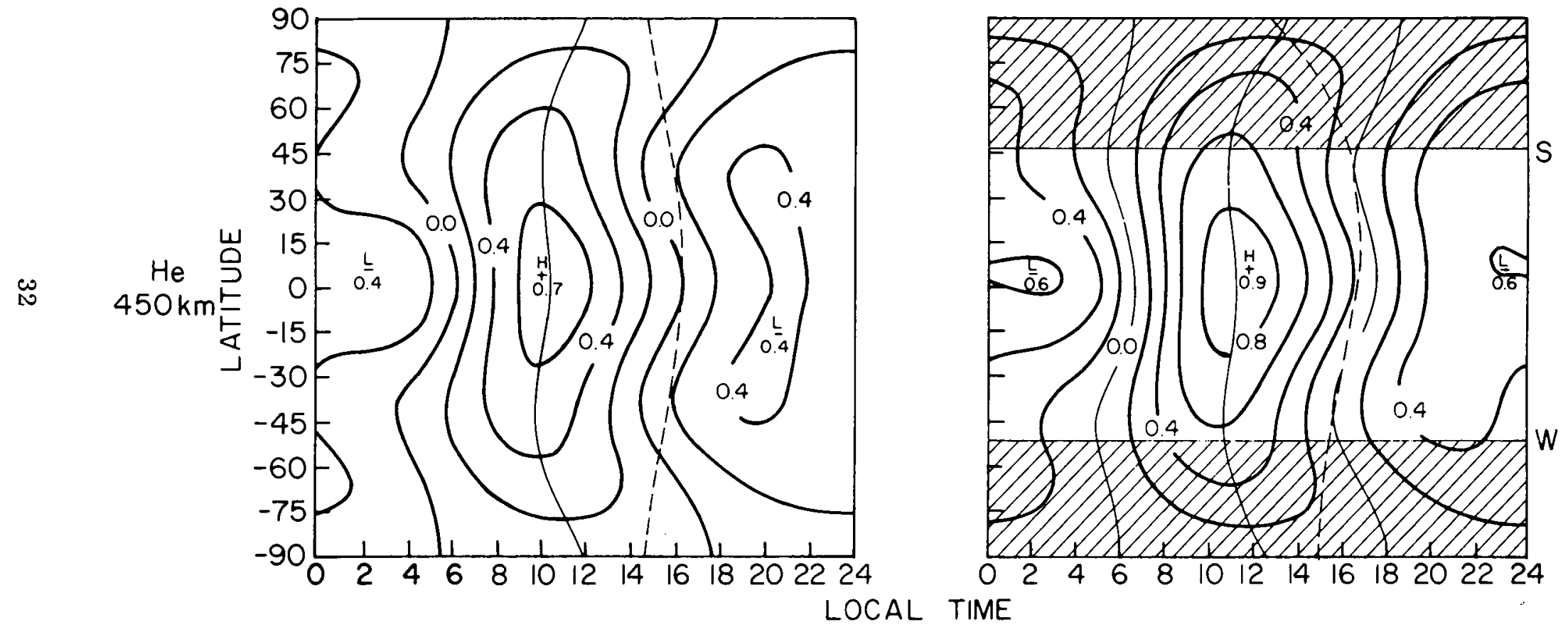

Figure 4. Contour plots of the logarithm (base e ) of the ratio of the $450 \mathrm{~km} \mathrm{He}$ densities to the local time average component for equinox and solstice conditions. 


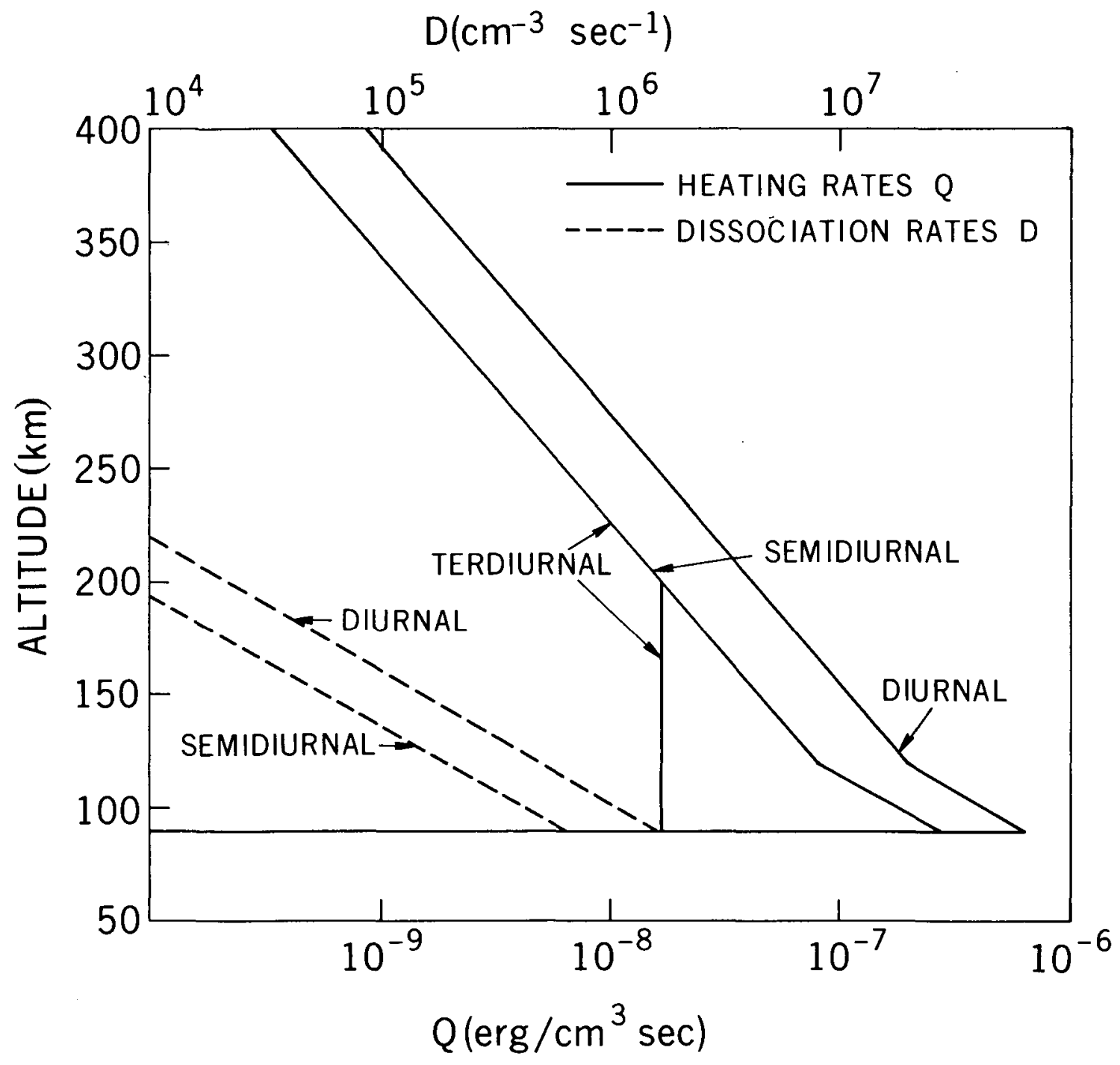

Figure 5. Height distribution of the amplitudes of the diurnal components of the heat input $Q$ (solid lines) and dissociation rates (dashed lines) $D$ at the equator. 


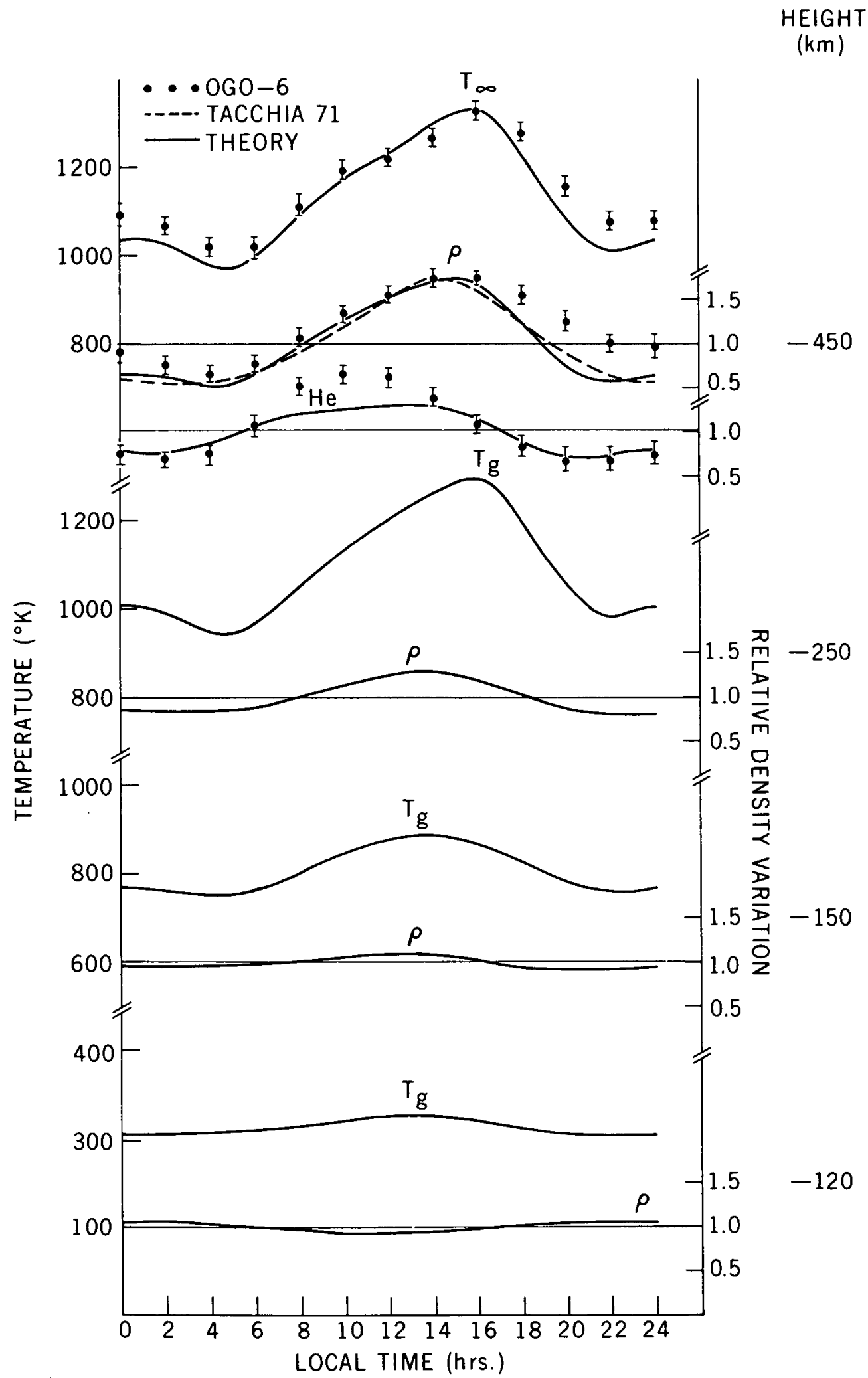

Figure 6. The theoretical diurnal variations in $\mathrm{He}$ at $450 \mathrm{~km}$ and in mass density and temperature at various heights are shown for the equator during equinox. At $450 \mathrm{~km}$ these results are compared with the corresponding OGO-6 oxygen and satellite drag mass density measurements. 


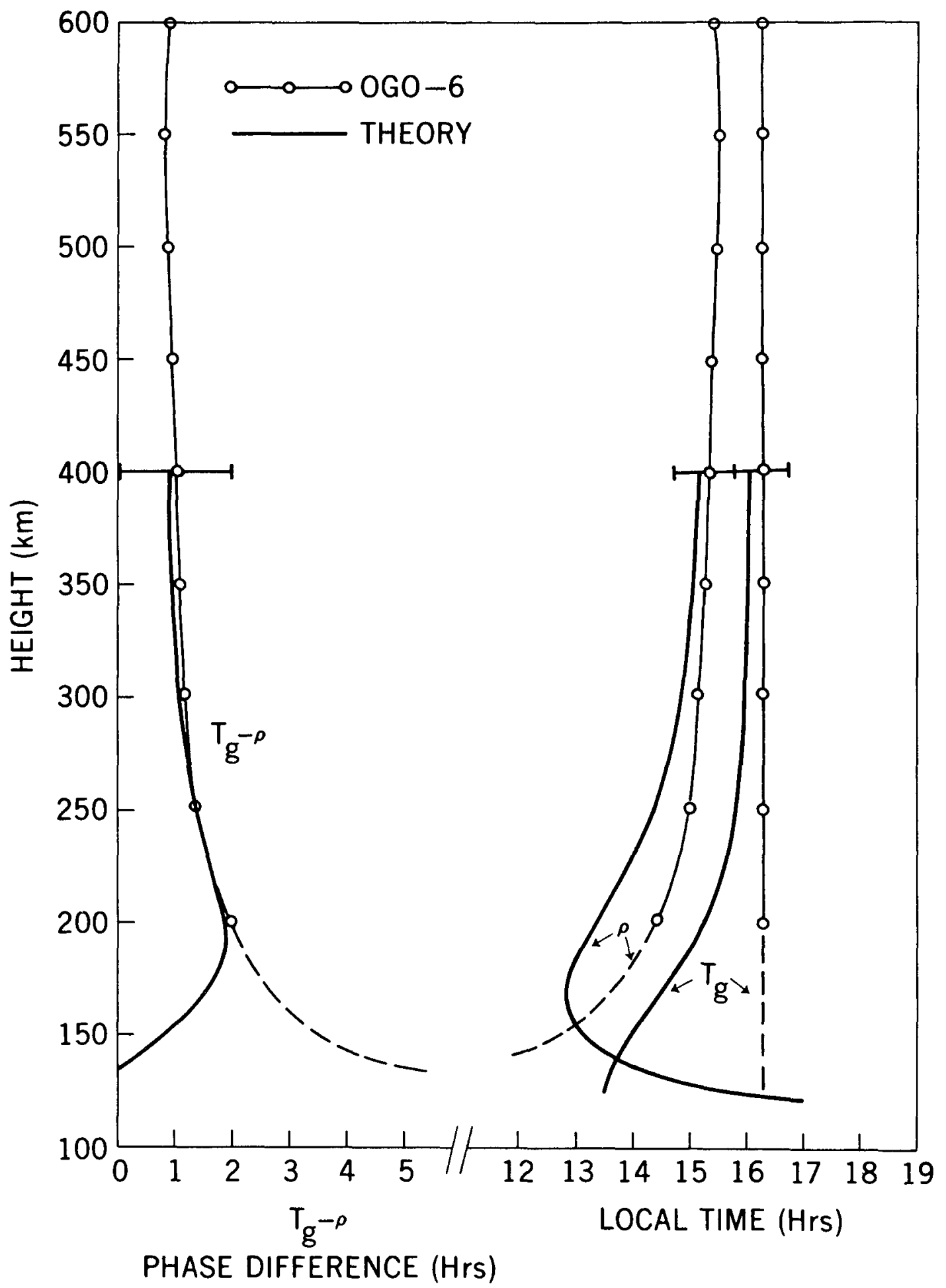

Figure 7. Height distribution of the phases of mass density and temperature from theory and inferred from OGO-6 neutral composition measurements around $450 \mathrm{~km}$. Below $250 \mathrm{~km}$ the OGO-6 extrapolations become uncertain as indicated with dashed lines. 

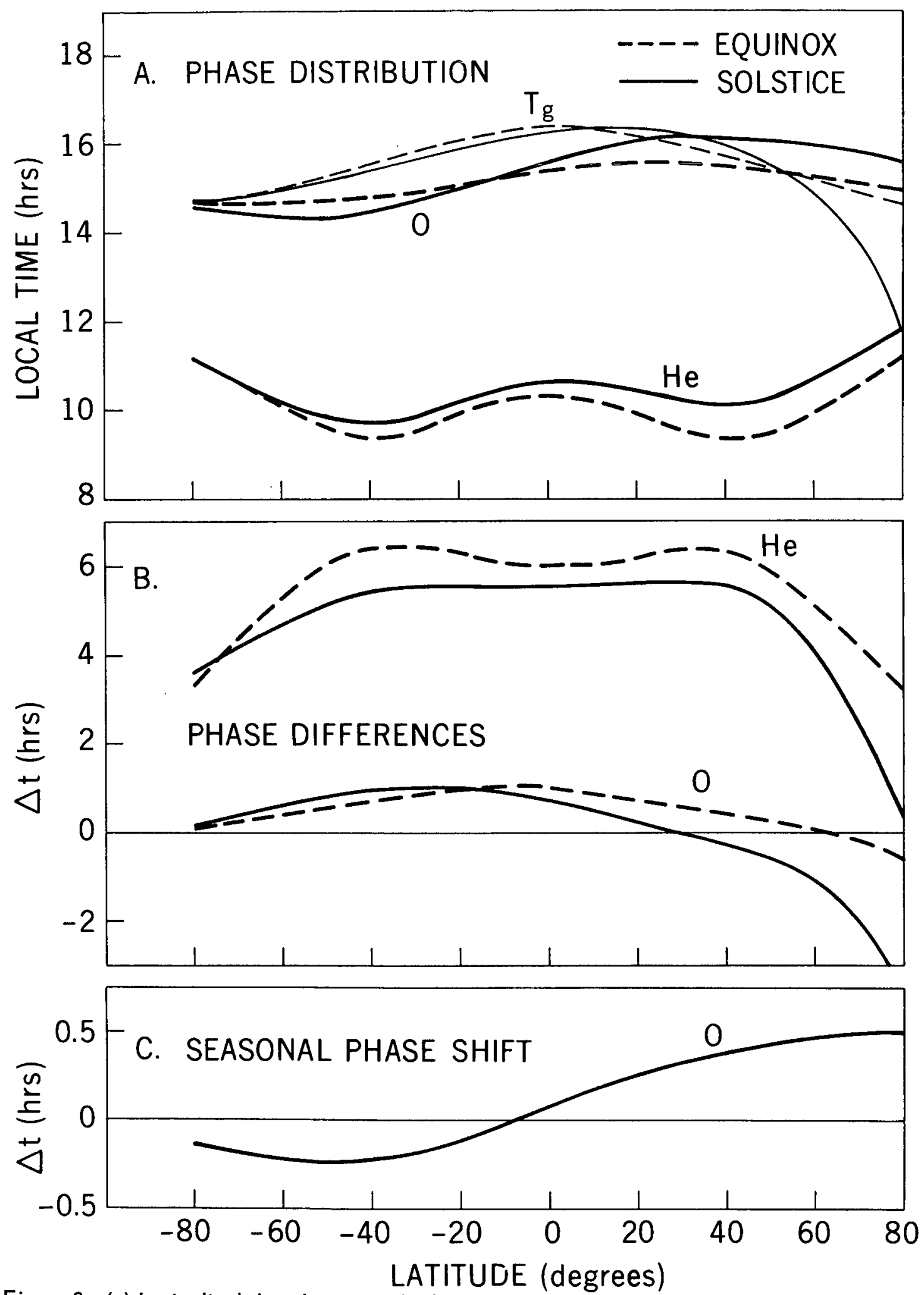

Figure 8. (a) Latitudinal distribution in the local times of maxima for $O$ and He (heavy lines) and $\mathrm{T}_{\mathrm{g}}$ (thin lines) at June solstice (solid lines) and September equinox (dashed lines) from the OGO-6

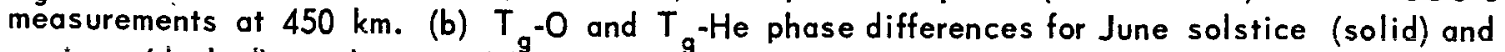
equinox (dashed) conditions. (c) Phase difference between June solstice and September equinox conditions of $O$. 


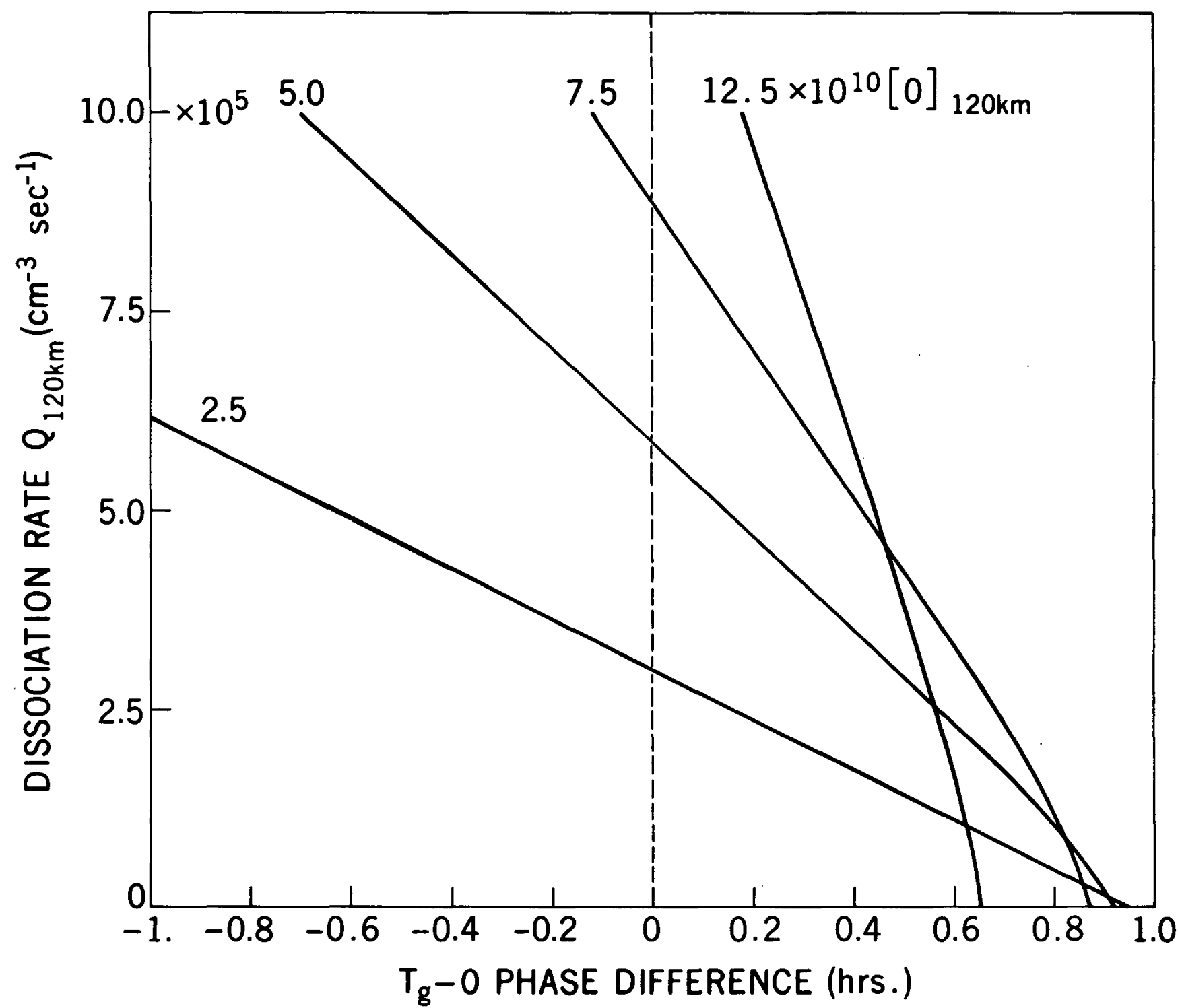

Figure 9. Phase difference for the diurnal component at $450 \mathrm{~km}$ as a function of the diurnal amplitude in the dissociation rate (ordinate) and the atomic oxygen concentration at $120 \mathrm{~km}$. Note the change in the phase sequence for low oxygen concentrations and high dissociation rates corresponding to summer conditions. 


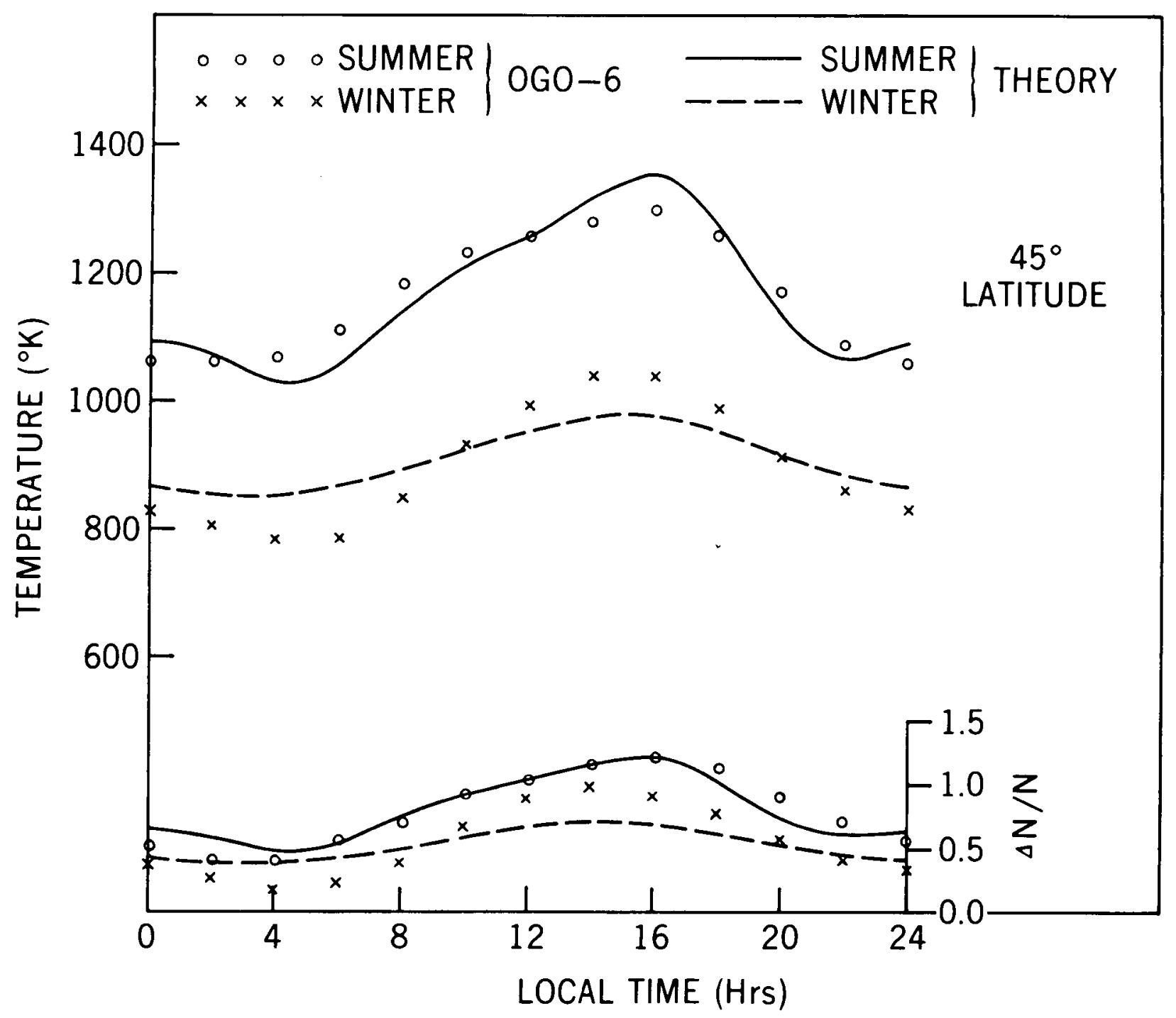

Figure 10. Diurnal variations in $T_{g}$ and $O$ for summer (solid lines) and winter (dashed lines) hemispheres from theory and OGO-6 observations at $45^{\circ}$ latitudes. The local time average temperatures and oxygen concentrations were adopted from the OGO-6 model (Hedin et al., 1973). 
Table 1

Temperature components at the equator

\begin{tabular}{|c|c|c|c|}
\hline & OGO-6 & $\begin{array}{c}\text { RADAR } \\
\text { (Salah and Evans) }\end{array}$ & THEORY \\
\cline { 2 - 5 } & $\Delta \mathrm{T} / \mathrm{T}$ (Phase) & $\Delta \mathrm{T} / \mathrm{T}$ (Phase) & $\Delta \mathrm{T} / \mathrm{T}$ (Phase) \\
\hline $\mathrm{P}_{1}^{1}$ (Diurnal) & $1.4^{-1}(15.0)$ & $1.5^{-1}(14.0)$ & $1.5^{-1}(14.4)$ \\
\hline $\mathrm{P}_{2}^{2}$ (Semidiurnal) & $1.7^{-2}(15.0)$ & $4.6^{-2}(16.0)$ & $4.2^{-2}(14.8)$ \\
\hline $\mathrm{P}_{3}^{3}$ (Terdiurnal) & $3.0^{-2}(16.7)$ & $3.4^{-2}(17.0)$ & $3.0^{-2}(16.5)$ \\
\hline
\end{tabular}

